\title{
JSH Consensus-Based Clinical Practice Guidelines for the Management of Hepatocellular Carcinoma: 2014 Update by the Liver Cancer Study Group of Japan
}

\author{
Masatoshi Kudo Osamu Matsui $^{\mathrm{b}}$ Namiki Izumic Hiroko Iijimad \\ Masumi Kadoya $\quad$ Yasuharu Imaif $^{f}$ Takuji Okusakag Shiro Miyayamah \\ Kaoru Tsuchiyac Kazuomi Ueshimaa Atsushi Hiraokai Masafumi Ikedaj \\ Sadahisa Ogasawarak Tatsuya Yamashital Tetsuya Minamim \\ Koichiro Yamakado ${ }^{n}$ on behalf of the Liver Cancer Study Group of Japan \\ aDepartment of Gastroenterology and Hepatology, Kinki University School of Medicine, Osaka, \\ bDepartment of Radiology, Kanazawa University Graduate School of Medical Science, Ishikawa, \\ 'Department of Gastroenterology and Hepatology, Musashino Red Cross Hospital, Tokyo, \\ dDivision of Hepatobiliary and Pancreatic Disease, Department of Internal Medicine, Hyogo College \\ of Medicine, Hyogo, eDepartment of Radiology, Shinshu University School of Medicine, Nagano, \\ fDepartment of Gastroenterology, Ikeda Municipal Hospital, Osaka, 9Department of Hepatobiliary \\ and Pancreatic Oncology, National Cancer Center Hospital, Tokyo, h' Department of Diagnostic Radiol- \\ ogy, Fukuiken Saiseikai Hospital, Fukui, iDepartment of Gastroenterology, Ehime Prefectural Central \\ Hospital, Ehime, jDepartment of Hepatobiliary and Pancreatic Oncology, National Cancer Center Hos- \\ pital East, Chiba, kDepartment of Gastroenterology and Nephrology, Graduate School of Medicine, \\ Chiba University, Chiba, 'Department of Gastroenterology and mDepartment of Radiology, Kanazawa \\ University Hospital, Ishikawa, n'Department of Interventional Radiology, Mie University School of \\ Medicine, Mie, Japan
}

\section{Key Words}

Clinical practice guidelines - Definition of transarterial chemoembolization failure .

Hepatocellular carcinoma. Japan Society of Hepatology · Liver Cancer Study Group of Japan

\author{
Abstract \\ The Clinical Practice Guidelines for the Management of Hepatocellular Carcinoma proposed \\ by the Japan Society of Hepatology was updated in June 2014 at a consensus meeting of the


Liver Cancer Study Group of Japan. Three important items have been updated: the surveillance and diagnostic algorithm, the treatment algorithm, and the definition of transarterial chemoembolization (TACE) failure/refractoriness. The most important update to the diagnostic algorithm is the inclusion of gadolinium-ethoxybenzyl-diethylenetriamine pentaacetic acid-enhanced magnetic resonance imaging as a first line surveillance/diagnostic tool. Another significant update concerns removal of the term "lipiodol" from the definition of TACE failure/refractoriness.

Copyright (C) 2014 S. Karger AG, Basel

\section{Introduction}

Four years have passed since the 2010 version of the Consensus-Based Clinical Practice Guidelines proposed by the Japan Society of Hepatology (JSH) [1] was adopted, and recent efforts have been made to produce a revised, updated version. Most members of JSH who specialize in liver cancer also belong to the Liver Cancer Study Group of Japan (LCSGJ); consequently, a consensus meeting was held at the 50th Annual Meeting of the Liver Cancer Study Group of Japan (June 5-6, 2014, Kyoto) (Congress President: Prof. Masatoshi Kudo) to update these clinical practice guidelines as proposed by JSH. At the consensus meeting, members discussed revision of (1) the surveillance and diagnostic algorithm, (2) the treatment algorithm, and (3) the definition of transarterial chemoembolization (TACE) failure. Approximately 350 experts in the diagnosis and treatment of liver cancer participated in this consensus development session. Items that were approved by at least $67 \%$ of experts through a voting system were included in the final version of the consensus-based guidelines. The Surveillance and Diagnostic Algorithm, Treatment Algorithm, and Definition of TACE Failure sections of the consensus-based guidelines were subsequently presented at The 4th International Kyoto Liver Cancer Symposium (4th IKLS; June 7-8, 2014, Kyoto) (Congress President: Prof. Masatoshi Kudo), and more than two-thirds of participants at this international symposium agreed the 2014 update of the Clinical Practice Guidelines proposed by the JSH-LCSGJ. Thus, the new versions of the surveillance and diagnostic algorithm, the treatment algorithm, and the definition of TACE failure are also recognized internationally.

\section{Surveillance and Diagnostic Algorithm}

Major changes were made to this section of the guidelines compared to the 2010 version. Revisions were based on the surveillance and diagnostic algorithm created primarily by Prof. Osamu Matsui as part of a research project supported by the Japanese Ministry of Health, Labour and Welfare (Primary Investigator: Prof. Shigeki Arii) [2]. Various studies have verified the usefulness of gadolinium-ethoxybenzyl-diethylenetriamine pentaacetic acid (Gd-EOB-DTPA)-enhanced magnetic resonance imaging (Gd-EOB-DTPA-MRI) in the diagnosis of hepatocellular carcinoma (HCC) [2-89], although this method is not yet included in the guidelines of the American Association for the Study of Liver Diseases [90], the European Association for the Study of the Liver [91], or the Asian Pacific Association for the Study of the Liver [92] guidelines [93, 94]. Only the updated JSH-LCSGJ diagnostic algorithm includes Gd-EOB-DTPA-MRI as a first-line surveillance and diagnostic tool for HCC. While surveillance of patients at super-high risk for HCC (i.e., those with hepatitis B or C cirrhosis) and patients at high risk for HCC (i.e., those with chronic hepatitis B/C or cirrhosis of another etiology) is essentially performed using ultrasonography (US) or tumor markers 
according to the JSH guideline $[1,95]$, it is recommended that super-high risk patients also undergo dynamic multidetector computed tomography (MDCT) or MRI every 6-12 months to pick up small HCC even when US shows no evidence of such a tumor [1,95]. At institutions specializing in liver cancer in Japan, it is recommended that Gd-EOB-DTPA-MRI be used instead of dynamic MDCT even when no tumor is detected on US. If Gd-EOB-DTPA-MRI shows a hypervascular mass with venous washout, a definitive diagnosis of HCC can be made. If Gd-EOB-DTPA-MRI shows a hypervascular mass without venous washout, a diagnosis of HCC can be made if the mass shows hypointensity in the hepatobiliary phase of Gd-EOB-DTPAMRI. Also, in this case, high-flow type hemangioma should be ruled out by using another modality because it can exhibit similar characteristics. If the mass is isointense or hyperintense in the hepatobiliary phase of Gd-EOB-DTPA-MRI, biopsy is necessary to confirm the diagnosis. Hypovascular masses on Gd-EOB-DTPA-MRI that are isointense or hyperintense in the hepatobiliary phase can enter the routine surveillance protocol. However, hypointense masses in the hepatobiliary phase have a high potential for malignant transformation $[9,11,18,22,23,37,40,41,54,55,59,86,96-102]$, and therefore contrast-enhanced ultrasonography (CEUS) using Sonazoid (Sonazoid CEUS) is strongly recommended. HCC can be correctly diagnosed by Sonazoid CEUS if hypervascularity and/or a defect in the Kupffer phase [103] is observed. Even when a mass is hypovascular on CEUS and there is no defect in the Kupffer phase, hypointensity in the hepatobiliary phase of Gd-EOB-DTPA-MRI is highly suggestive of malignancy [7]. Accordingly, biopsy is recommended for small nodules of 1-1.5 cm or larger for differential diagnosis between early HCC [103] and a dysplastic nodule (DN). If a mass is diagnosed as a DN or a borderline lesion, intensive follow-up every 3 to 6 months with GD-EOB-DTPA-MRI (or dynamic MDCT) is recommended. The intensive follow-up is also recommended for small nodules of less than 1-1.5 cm (fig. 1).

Of course, institutions that cannot perform GD-EOB-DTPA-MRI every 6-12 months as the first-line modality may use dynamic MDCT as the first step of screening when no nodule is evident on US, but it is absolutely essential to perform GD-EOB-DTPA-MRI or Sonazoid CEUS when dynamic MDCT does not show hallmark of HCC (i.e., arterial enhancement with venous washout) in the mass detected by MDCT. This algorithm was approved by more than $90 \%$ of participants and is, therefore, now the new surveillance and diagnostic algorithm recommended by the JSH and LCSGJ (fig. 1).

\section{Treatment Algorithm}

No new treatments or molecular targeted agents have been developed for HCC since the 2010 JSH consensus-based treatment algorithm [1,104] was adopted, so few changes were made to this section.

Decreased uptake in the Kupffer phase on CEUS was added to the third item of the annotations as an indicative finding in the diagnosis of early HCC [103]. In addition, although sorafenib is recommended for patients with minor portal vein invasion or portal invasion at the first portal branch (Vp1-3), the new algorithm reflects the consensus that it is not recommended for patients with portal invasion at the main portal branch (Vp4) due to the risk of hepatic failure. However, hepatic arterial infusion chemotherapy (HAIC) is still strongly recommended for patients with $\mathrm{Vp} 4$, and therefore recommendations regarding HAIC were left unchanged [105]. Moreover, because locoregional therapy for Child-Pugh C patients is now widely used and many studies have reported its survival benefits, it is now described as a "well accepted treatment" rather than an "experimental treatment" in the revised algorithm (fig. 2) [106-110]. 


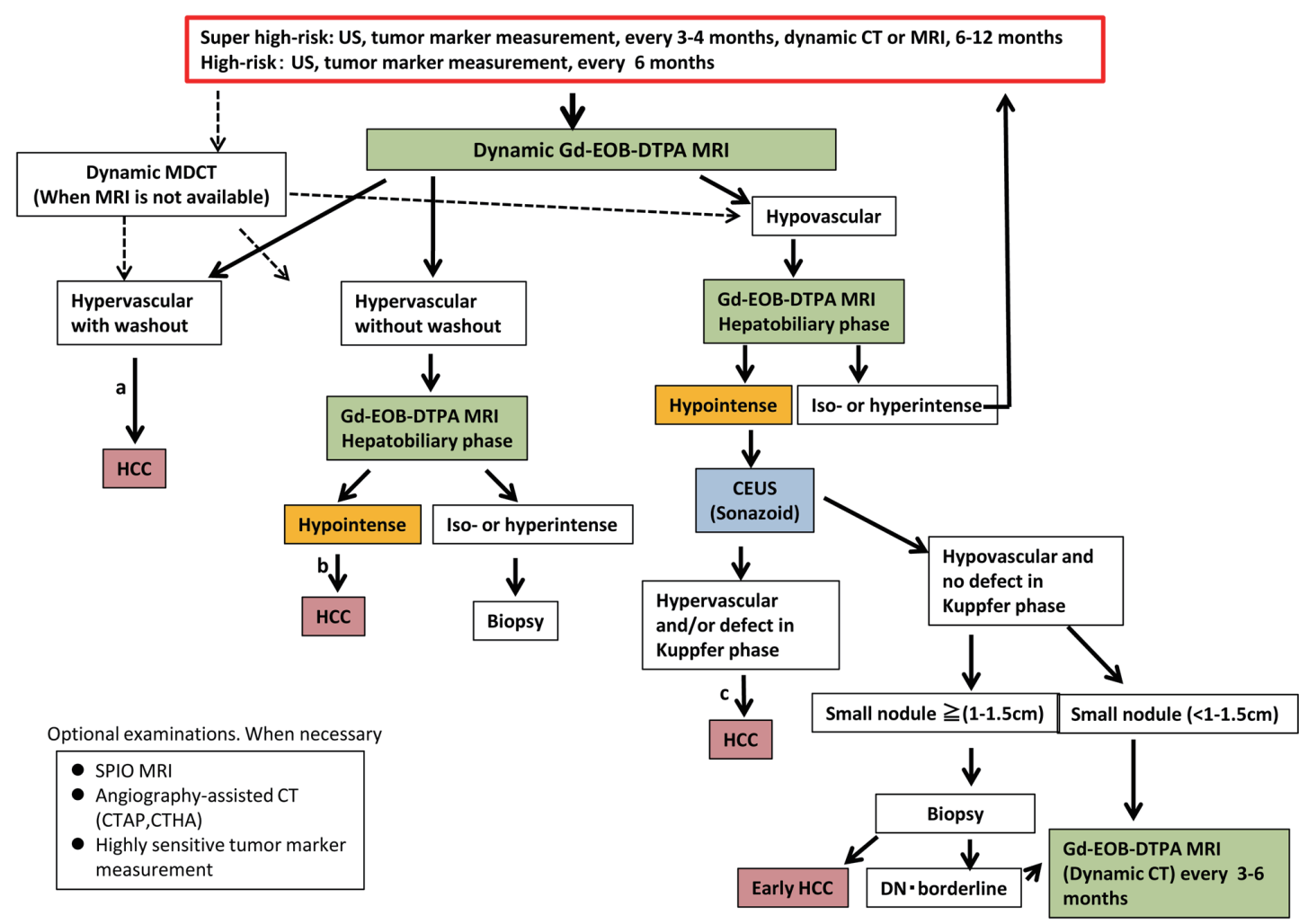

Fig. 1. Surveillance and Diagnostic Algorithm of HCC (Proposed by the Liver Cancer Study Group of Japan 2014). SPIO=superparamagnetic iron oxide; CTAP=computed tomographic arterial portography; CTHA=computed tomographic hepatic arteriography.

${ }^{a}$ Cavernous hemangioma may show hypointensity on equilibrium (transitional) phase of dynamic GdEOB-DTPA MRI (pseudo-washout). It should be excluded by other sequences of MRI and/or other imaging modalities. ${ }^{\mathrm{b} C a v e r n o u s ~ h e m a n g i o m a ~ u s u a l l y ~ s h o w s ~ h y p o i n t e n s i t y ~ o n ~ h e p a t o b i l i a r y ~ p h a s e ~ o f ~ G d-E O B-D T-~}$ PA MRI. It should be excluded by other sequences of MRI and/or other imaging modalities. 'Biopsy may be considered for confirmation.

\section{Definition of TACE Failure/Refractoriness}

In the 2010 version of the JSH consensus-based treatment algorithm [1], TACE failure/ refractoriness was defined assuming the use of superselective lipiodol TACE-which has been widely used worldwide and particularly in Japan - and areas with lipiodol deposition were considered to be necrotic. However, this concept is not well accepted internationally [111]. Furthermore, following the approval in Japan in February 2014 of emolic drug-eluting beads, an embolic material that does not use lipiodol, the phrase needed to be changed from "lipiodol deposition" to "necrotic lesion or viable lesion." Accordingly, the section was revised to define TACE failure as an ineffective response after two or more consecutive TACE procedures that is evident on response evaluation CT or MRI after 1-3 months, even after chemotherapeutic agents are changed and/or the feeding artery is reanalyzed. In addition, the appearance of more lesions in the liver than the number of lesions recorded at the previous TACE procedure (other than the nodule being treated) was added definition of TACE failure/refractoriness. Following discussion of the other issues concerning continuous elevation of tumor markers, vascular invasion, and extrahepatic spread, descriptions similar to those in the previous version were approved (table 1). The revision of these TACE failure definitions were approved by more than $85 \%$ of HCC experts. 


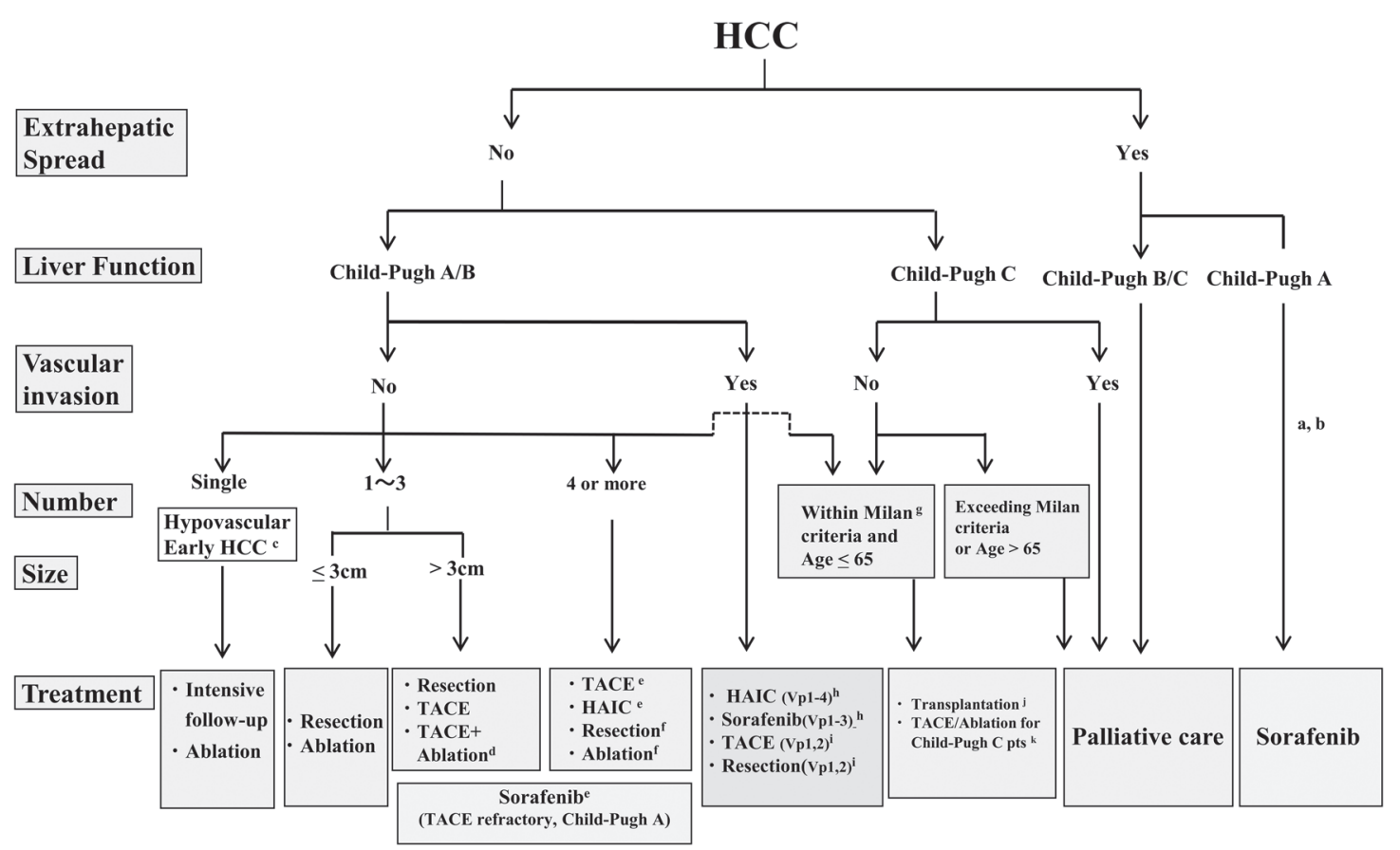

Fig. 2. JSH-LCSGJ Consensus-based Treatment Algorithm for Hepatocellular Carcinoma revised in 2014. aTreatment should be performed as if extrahepatic spread is negative when extrahepatic spread is not regarded as a prognostic factor. ${ }^{b}$ Sorafenib is the first choice of treatment in this setting as a standard of care. 'Intensive follow-up observation is recommended for hypovascular nodules by the Japanese Evidence-Based Clinical Practice Guidelines. However, local ablation therapy is frequently performed in the following cases: 1) when the nodule is diagnosed pathologically as early HCC, 2) when the nodules show decreased uptake on hepatobiliary phase Gd-EOB-DTPA-MRI, 3) when the nodules show decreased portal flow by CTAP or 4) decreased uptake is shown on Kupffer phase of Sonazoid enhanced US, since these nodules are known to frequently progress to the typical hypervascular HCC. ${ }^{\mathrm{d}}$ Even for HCC nodules exceeding $3 \mathrm{~cm}$ in diameter, combination therapy of TACE and ablation is frequently performed when resection is not indicated. Transcatheter arterial chemoembolization (TACE) is the first choice of treatment in this setting. Hepatic arterial infusion chemotherapy (HAIC) using reservoir system is also recommended for TACE refractory patients. The regimen for this treatment is usually low-dose FP (5FU+CDDP) or 5FU infusion combined with systemic interferon therapy. Sorafenib is also a treatment of choice for TACE refrac-

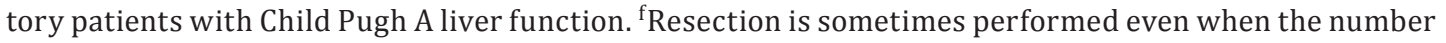
of nodules is greater than 4. Furthermore, ablation is sometimes performed in combination with TACE. gMilan criteria: Tumor size $\leq 3 \mathrm{~cm}$ and tumor number $\leq 3$; or solitary tumor $\leq 5 \mathrm{~cm}$. Even when liver function is good (Child-Pugh A/B), transplantation is sometimes considered for frequently recurring HCC pa-

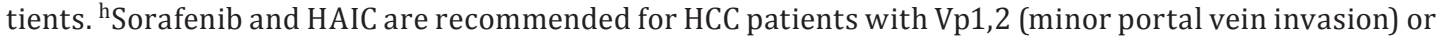
Vp3 (portal invasion at the 1st portal branch). Sorafenib is not recommended for HCC patients with Vp4 (portal invasion at the main portal branch), whereas HAIC is recommended for such patients with tumor thrombus in the main portal branch. ${ }^{i}$ Resection and TACE is frequently performed when portal invasion is minor such as Vp1 (portal invasion at the 3rd or more peripheral portal branch) or Vp2 (portal inva-

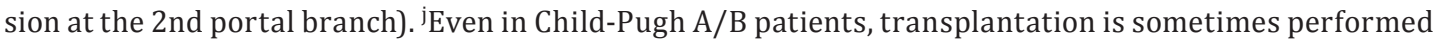
for relatively younger patients with frequently or early recurring HCC after curative treatments. ${ }^{\mathrm{k}}$ Local ablation therapy or subsegmental TACE is performed even for Child-Pugh C patients (CP score 10 and 11) within Milan criteria when transplantation is not indicated. In the case, patients with no hepatic encephalopathy, no uncontrollable ascites, and a low bilirubin level $(<3.0 \mathrm{mg} / \mathrm{dl})$ are selected for treatment. Although these are well-accepted treatments in the routine clinical setting, there is no high-level evidence of its survival benefit in Child-Pugh C patients. A prospective study is necessary to clarify this issue. 
Table 1. Definition of TACE Failure/Refractoriness (LCSGJ)

(1) Intrahepatic lesion

i. Two or more consecutive ineffective responses seen within the treated tumors (viable lesion $>50 \%$ ), even after changing the chemotherapeutic agents and/or reanalysis of feeding artery, on response evaluation CT/MRI after 1-3 months following adequately performed selective TACE

ii. Two or more consecutive progressions in the liver (including an increase in the number of tumors compared to that before the previous TACE procedure), even after changing the chemotherapeutic agents and/or reanalysis of feeding artery, on response evaluation CT/MRI after 1-3 months following adequately performed selective TACE

(2) Tumor marker

Continuous elevation of tumor markers right after TACE even though transient minor reduction is observed.

(3) Appearance of vascular invasion

(4) Appearance of extrahepatic spread

\section{Conclusion}

We report here the 2014 updated versions of the Surveillance and Diagnostic Algorithm, Treatment Algorithm, and Definition of TACE Failure/Refractoriness sections of the 2010 Consensus-Based Clinical Practice Guidelines proposed by JSH that were discussed and approved at the consensus meeting held at the 50th Annual Meeting of the Liver Cancer Study Group of Japan (June 5-6, 2014, Kyoto).

\section{References}

1 Kudo M, Izumi N, Kokudo N, Matsui O, Sakamoto M, Nakashima O, Kojiro M, Makuuchi M, HCC Expert Panel of Japan Society of Hepatology: Management of hepatocellular carcinoma in Japan: Consensus-Based Clinical Practice Guidelines proposed by the Japan Society of Hepatology (JSH) 2010 updated version. Dig Dis 2011;29:339-364.

2 Kudo M, Matsui O, Sakamoto M, Kitao A, Kim T, Ariizumi S, Ichikawa T, Kobayashi S, Imai Y, Izumi N, Fujinaga Y, Arii S: Role of gadolinium-ethoxybenzyl-diethylenetriamine pentaacetic acid-enhanced magnetic resonance imaging in the management of hepatocellular carcinoma: consensus at the Symposium of the 48th Annual Meeting of the Liver Cancer Study Group of Japan. Oncology 2013;84(Suppl 1):21-27.

-3 Fujita N, Nishie A, Kubo Y, Asayama Y, Ushijima Y, Takayama Y, Moirta K, Shirabe K, Aishima S, Honda H: Hepatocellular carcinoma: clinical significance of signal heterogeneity in the hepatobiliary phase of gadoxetic acid-enhanced MR imaging. Eur Radiol 2014, Epub ahead of print.

4 Junqiang L, Yinzhong W, Li Z, Shunlin G, Xiaohui W, Yanan Z, Kehu Y: Gadoxetic acid disodium (GdEOBDTPA)-enhanced magnetic resonance imaging for the detection of hepatocellular carcinoma: a metaanalysis. J Magn Reson Imaging 2014;39:1079-1087.

5 Faletti R, Cassinis MC, Fonio P, Bergamasco L, Pavan LJ, Rapellino A, David E, Gandini G: Multiparametric Gd-EOB-DTPA magnetic resonance in diagnosis of HCC: dynamic study, hepatobiliary phase, and diffusion-weighted imaging compared to histology after orthotopic liver transplantation. Abdom Imaging 2014, Epub ahead of print.

6 Ueno A, Masugi Y, Yamazaki K, Komuta M, Effendi K, Tanami Y, Tsujikawa H, Tanimoto A, Okuda S, Itano O, Kitagawa Y, Kuribayashi S, Sakamoto M: OATP1B3 expression is strongly associated with Wnt/ $\beta$-catenin signaling and represents the transporter of gadoxetic acid in hepatocellular carcinoma. J Hepatol 2014, Epub ahead of print.

7 Ichikawa T, Sano K, Morisaka H: Diagnosis of pathologically early HCC with EOB-MRI: experiences and current consensus. Liver Cancer 2014;3:97-107. 
8 Chang WC, Chen RC, Chou CT, Lin CY, Yu CY, Liu CH, Chou JM, Hsu HH, Huang GS: Histological grade of hepatocellular carcinoma correlates with arterial enhancement on gadoxetic acid-enhanced and diffusionweighted MR images. Abdom Imaging 2014, Epub ahead of print.

-9 Matsuda M, Tsuda T, Yoshioka S, Murata S, Tanaka H, Hirooka M, Hiasa Y, Mochizuki T: Incidence for progression of hy pervascular HCC in hypovascular hepatic nodules showing hyperintensity on gadoxetic acidenhanced hepatobiliary phase in patients with chronic liver diseases. Jpn J Radiol 2014;32:405-413.

10 Shim JH, Han S, Shin YM, Lee YJ, Lee SG, Kim KM, Lim YS, Lee HC: Prognostic performance of preoperative gadoxetic acid-enhanced MRI in resectable hepatocellular carcinoma. J Magn Reson Imaging 2014, Epub ahead of print.

11 Jang KM, Kim SH, Kim YK, Choi D: Imaging features of subcentimeter hypointense nodules on gadoxetic acid-enhanced hepatobiliary phase MR imaging that progress to hypervascular hepatocellular carcinoma in patients with chronic liver disease. Acta Radiol 2014, Epub ahead of print.

-12 Matsuda M, Ichikawa T, Amemiya H, et al: Preoperative gadoxetic acid-enhanced MRI and simultaneous treatment of early hepatocellular carcinoma prolonged recurrence-free survival of progressed hepatocellular carcinoma patients after hepatic resection. HPB Surg 2014;2014:641685, in press.

-13 Yamashita T, Kitao A, Matsui O, Hayashi T, Nio K, Kondo M, Ohno N, Miyati T, Okada H, Yamashita T, Mizukoshi E, Honda M, Nakanuma Y, Takamura H, Ohta T, Nakamoto Y, Yamamoto M, Takayama T, Arii S, Wang XW, Kaneko S: Gd-EOB-DTPA-enhanced magnetic resonance imaging and alpha-fetoprotein predict prognosis of early-stage hepatocellular carcinoma. Hepatology 2014, Epub ahead of print.

-14 Park VY, Choi JY, Chung YE, Kim H, Park MS, Lim JS, Kim KW, Kim MJ: Dynamic enhancement pattern of HCC smaller than $3 \mathrm{~cm}$ in diameter on gadoxetic acid-enhanced MRI: comparison with multiphasic MDCT. Liver Int 2014, Epub ahead of print.

15 Ishimaru H, Nakashima K, Sakugawa T, Sakamoto A, Matsuoka Y, Ashizawa K, Uetani M: Local recurrence after chemoembolization of hepatocellular carcinoma: uptake of gadoxetic acid as a new prognostic factor. AJR Am J Roentgenol 2014;202:744-751.

16 Yu MH, Kim JH, Yoon JH, Kim HC, Chung JW, Han JK, Choi BI: Small ( $\leq 1-\mathrm{cm})$ hepatocellular carcinoma: diagnostic performance and imaging features at gadoxetic acid-enhanced MR imaging. Radiology 2014;271:748760.

17 Tada T, Kumada T, Toyoda H, Ito T, Sone Y, Okuda S, Ogawa S, Igura T, Imai Y: Diagnostic accuracy for macroscopic classification of nodular hepatocellular carcinoma: comparison of gadolinium ethoxybenzyl diethylenetriamine pentaacetic acid-enhanced magnetic resonance imaging and angiography-assisted computed tomography. J Gastroenterol 2014, Epub ahead of print.

18 Komatsu N, Motosugi U, Maekawa S, Shindo K, Sakamoto M, Sato M, Tatsumi A, Miura M, Amemiya F, Nakayama Y, Inoue T, Fukasawa M, Uetake T, Ohtaka M, Sato T, Asahina Y, Kurosaki M, Izumi N, Ichikawa T, Araki T, Enomoto N: Hepatocellular carcinoma risk assessment using gadoxetic acid-enhanced hepatocyte phase magnetic resonance imaging. Hepatol Res 2014, Epub ahead of print.

19 Kim KA, Kim MJ, Choi JY, Park MS, Lim JS, Chung YE, Kim KW: Detection of recurrent hepatocellular carcinoma on post-operative surveillance: comparison of MDCT and gadoxetic acid-enhanced MRI. Abdom Imaging 2014;39:291-299.

20 Phongkitkarun S, Limsamutpetch K, Tannaphai P, Jatchavala J: Added value of hepatobiliary phase gadoxetic acid-enhanced MRI for diagnosing hepatocellular carcinoma in high-risk patients. World J Gastroenterol 2013;19:8357-8365.

-21 Zhao XT, Li WX, Chai WM, Chen KM: Detection of small hepatocellular carcinoma using gadoxetic acidenhanced MRI: Is the addition of diffusion-weighted MRI at 3.0T beneficial? J Dig Dis 2014;15:137-145.

22 Iannicelli E, Di Pietropaolo M, Marignani M, Briani C, Federici GF, Delle Fave G, David V: Gadoxetic acidenhanced MRI for hepatocellular carcinoma and hypointense nodule observed in the hepatobiliary phase. Radiol Med (Torino) 2014;119:367-376.

23 Inoue T, Hyodo T, Murakami T, Takayama Y, Nishie A, Higaki A, Korenaga K, Sakamoto A, Osaki Y, Aikata H, Chayama K, Suda T, Takano T, Miyoshi K, Koda M, Numata K, Tanaka H, Iijima H, Ochi H, Hirooka M, Imai Y, Kudo M: Hypovascular hepatic nodules showing hy pointense on the hepatobiliary-phase image of Gd-EOBDTPA-enhanced MRI to develop a hypervascular hepatocellular carcinoma: a nationwide retrospective study on their natural course and risk factors. Dig Dis 2013;31:472-479.

24 Park MJ, Kim YK, Park HJ, Hwang J, Lee WJ: Scirrhous hepatocellular carcinoma on gadoxetic acid-enhanced magnetic resonance imaging and diffusion-weighted imaging: emphasis on the differentiation of intrahepatic cholangiocarcinoma. J Comput Assist Tomogr 2013;37:872-881.

25 Kakihara D, Nishie A, Harada N, Shirabe K, Tajima T, Asayama Y, Ishigami K, Nakayama T, Takayama Y, Okamoto D, Fujita N, Kishimoto J, Honda H: Performance of gadoxetic acid-enhanced MRI for detecting hepatocellular carcinoma in recipients of living-related-liver-transplantation: Comparison with dynamic multidetector row computed tomography and angiography-assisted computed tomography. J Magn Reson Imaging 2013, Epub ahead of print.

26 Nishie A, Asayama Y, Ishigami K, Kakihara D, Nakayama T, Ushijima Y, Takayama Y, Shirabe K, Fujita N, Kubo Y, Hirakawa M, Honda H: Clinicopathological significance of the peritumoral decreased uptake area of gadolinium ethoxybenzyl diethylenetriamine pentaacetic acid in hepatocellular carcinoma. J Gastroenterol Hepatol 2014;29:561-567.

-27 Hamada K, Saitoh S, Nishino N, Nakazawa T, Tobayashi K, Takano Y, Sakuma H: A liver tumor that progressed to hepatocellular carcinoma as observed on follow-up magnetic resonance images showing increased contrast medium uptake. Nippon Shokakibyo Gakkai Zasshi 2013;110:1976-1982. 
28 Lim S, Kim YK, Park HJ, Lee WJ, Choi D, Park MJ: Infiltrative hepatocellular carcinoma on gadoxetic acidenhanced and diffusion-weighted MRI at 3.0T. J Magn Reson Imaging 2014;39:1238-1245.

29 Cha DI, Lee MW, Kim YK, Kim SH, Park HJ, Rhim H, Lim HK: Assessing patients with hepatocellular carcinoma meeting the Milan criteria: Is liver 3 tesla MR with gadoxetic acid necessary in addition to liver CT? J Magn Reson Imaging 2014;39:842-852.

-30 Liu X, Zou L, Liu F, Zhou Y, Song B: Gadoxetic acid disodium-enhanced magnetic resonance imaging for the detection of hepatocellular carcinoma: a meta-analysis. PLoS ONE 2013;8:e70896.

-31 Wu LM, Xu JR, Gu HY, Hua J, Chen J, Zhu J, Zhang W, Hu J: Is liver-specific gadoxetic acid-enhanced magnetic resonance imaging a reliable tool for detection of hepatocellular carcinoma in patients with chronic liver disease? Dig Dis Sci 2013;58:3313-3325.

-32 Kim JY, Lee SS, Byun JH, Kim SY, Park SH, Shin YM, Lee MG: Biologic factors affecting HCC conspicuity in hepatobiliary phase imaging with liver-specific contrast agents. AJR Am J Roentgenol 2013;201:322-331.

-33 Baird AJ, Amos GJ, Saad NF, Benson MD: Retrospective audit to determine the diagnostic accuracy of Primovist-enhanced MRI in the detection of hepatocellular carcinoma in cirrhosis with explant histopathology correlation. J Med Imaging Radiat Oncol 2013;57:314-320.

-34 Yamamoto A, Ito K, Tamada T, Higaki A, Kanki A, Sato T, Tanimoto D: Newly developed hypervascular hepatocellular carcinoma during follow-up periods in patients with chronic liver disease: observation in serial gadoxetic acid-enhanced MRI. AJR Am J Roentgenol 2013;200:1254-1260.

35 Park YS, Lee CH, Kim BH, Lee J, Choi JW, Kim KA, Ahn JH, Park CM: Using Gd-EOB-DTPA-enhanced 3-T MRI for the differentiation of infiltrative hepatocellular carcinoma and focal confluent fibrosis in liver cirrhosis. Magn Reson Imaging 2013;31:1137-1142.

- 36 Yoo SH, Choi JY, Jang JW, Bae SH, Yoon SK, Kim DG, Yoo YK, Rha SE, Lee YJ, Jung ES: Gd-EOB-DTPA-enhanced MRI is better than MDCT in decision making of curative treatment for hepatocellular carcinoma. Ann Surg Oncol 2013;20:2893-2900.

-37 Ichikawa S, Ichikawa T, Motosugi U, Sano K, Morisaka H, Enomoto N, Matsuda M, Fujii H, Araki T: Presence of a hypovascular hepatic nodule showing hypointensity on hepatocyte-phase image is a risk factor for hypervascular hepatocellular carcinoma. J Magn Reson Imaging 2014;39:293-297.

-38 Kim SH, Jeong WK, Kim Y, Kim MY, Kim J, Pyo JY, Oh YH: Hepatocellular carcinoma composed of two different histologic types: imaging features on gadoxetic acid-enhanced liver MRI. Clin Mol Hepatol 2013;19:92-96.

-39 Choi JW, Lee JM, Kim SJ, Yoon JH, Baek JH, Han JK, Choi BI: Hepatocellular carcinoma: imaging patterns on gadoxetic acid-enhanced MR images and their value as an imaging biomarker. Radiology 2013;267:776786.

40 Toyoda H, Kumada T, Tada T, Niinomi T, Ito T, Sone Y, Kaneoka Y, Maeda A: Non-hypervascular hypointense nodules detected by Gd-EOB-DTPA-enhanced MRI are a risk factor for recurrence of HCC after hepatectomy. J Hepatol 2013;58:1174-1180.

-41 Hyodo T, Murakami T, Imai Y, Okada M, Hori M, Kagawa Y, Kogita S, Kumano S, Kudo M, Mochizuki T: Hypovascular nodules in patients with chronic liver disease: risk factors for development of hypervascular hepatocellular carcinoma. Radiology 2013;266:480-490.

-42 Ooka Y, Kanai F, Okabe S, Ueda T, Shimofusa R, Ogasawara S, Chiba T, Sato Y, Yoshikawa M, Yokosuka O: Gadoxetic acid-enhanced MRI compared with CT during angiography in the diagnosis of hepatocellular carcinoma. Magn Reson Imaging 2013;31:748-754.

-43 Granito A, Galassi M, Piscaglia F, Romanini L, Lucidi V, Renzulli M, Borghi A, Grazioli L, Golfieri R, Bolondi L: Impact of gadoxetic acid (Gd-EOB-DTPA)-enhanced magnetic resonance on the non-invasive diagnosis of small hepatocellular carcinoma: a prospective study. Aliment Pharmacol Ther 2013;37:355-363.

44 Kitao A, Matsui O, Yoneda N, Kozaka K, Kobayashi S, Koda W, Gabata T, Yamashita T, Kaneko S, Nakanuma Y, Kita R, Arii S: Hypervascular hepatocellular carcinoma: correlation between biologic features and signal intensity on gadoxetic acid-enhanced MR images. Radiology 2012;265:780-789.

45 Park MJ, Kim YK, Lee MH, Lee JH: Validation of diagnostic criteria using gadoxetic acid-enhanced and diffusion-weighted MR imaging for small hepatocellular carcinoma $(<=2.0 \mathrm{~cm})$ in patients with hepatitisinduced liver cirrhosis. Acta Radiol 2013;54:127-136.

46 Jin YJ, Nah SY, Lee JW, Lee JI, Jeong S, Lee DH, Kim YS, Cho SG, Jeon YS: Utility of adding Primovist magnetic resonance imaging to analysis of hepatocellular carcinoma by liver dynamic computed tomography. Clin Gastroenterol Hepatol 2013;11:187-192.

47 An C, Park MS, Kim D, Kim YE, Chung WS, Rhee H, Kim MJ, Kim KW: Added value of subtraction imaging in detecting arterial enhancement in small $(<3 \mathrm{~cm})$ hepatic nodules on dynamic contrast-enhanced MRI in patients at high risk of hepatocellular carcinoma. Eur Radiol 2013;23:924-930.

-48 Shinagawa Y, Sakamoto K, Fujimitsu R, Shimakura M, Kora S, Takano K, Yoshimitsu K: Pseudolesion of the liver on gadoxetate disodium-enhanced MR images obtained after transarterial chemoembolization for hepatocellular carcinoma: clinicoradiologic correlation. AJR Am J Roentgenol 2012;199:1010-1017.

49 Nakamura Y, Tashiro H, Nambu J, Ohdan H, Kakizawa H, Date S, Awai K: Detectability of hepatocellular carcinoma by gadoxetate disodium-enhanced hepatic MRI: tumor-by-tumor analysis in explant livers. J Magn Reson Imaging 2013;37:684-691.

50 Bashir MR, Gupta RT, Davenport MS, Allen BC, Jaffe TA, Ho LM, Boll DT, Merkle EM: Hepatocellular carcinoma in a North American population: does hepatobiliary MR imaging with Gd-EOB-DTPA improve sensitivity and confidence for diagnosis? J Magn Reson Imaging 2013;37:398-406. 
51 Fujinaga Y, Kadoya M, Kozaka K, Shinmura R, Matsui O, Takayama T, Yamamoto M, Kokudo N, Kawasaki S, Arii S: Prediction of macroscopic findings of hepatocellular carcinoma on hepatobiliary phase of gadolinium-ethoxybenzyl-diethylenetriamine pentaacetic acid-enhanced magnetic resonance imaging: Correlation with pathology. Hepatol Res 2013;43:488-494.

-52 Kim JY, Kim MJ, Kim KA, Jeong HT, Park YN: Hyperintense HCC on hepatobiliary phase images of gadoxetic acid-enhanced MRI: correlation with clinical and pathological features. Eur J Radiol 2012;81:3877-3882.

53 Kanata N, Yoshikawa T, Ohno Y, Kanda T, Uchida K, Izaki K, Fukumoto T, Ku Y, Itoh T, Kitajima K, Takahashi S, Sugimura K: HCC-to-liver contrast on arterial-dominant phase images of EOB-enhanced MRI: comparison with dynamic CT. Magn Reson Imaging 2013;31:17-22.

54 Kim YK, Lee WJ, Park MJ, Kim SH, Rhim H, Choi D: Hypovascular hypointense nodules on hepatobiliary phase gadoxetic acid-enhanced MR images in patients with cirrhosis: potential of DW imaging in predicting progression to hypervascular HCC. Radiology 2012;265:104-114.

55 Kobayashi S, Matsui O, Gabata T, Koda W, Minami T, Ryu Y, Kozaka K, Kitao A: Intranodular signal intensity analysis of hypovascular high-risk borderline lesions of HCC that illustrate multi-step hepatocarcinogenesis within the nodule on Gd-EOB-DTPA-enhanced MRI. Eur J Radiol 2012;81:3839-3845.

56 Kim AY, Kim YK, Lee MW, Park MJ, Hwang J, Lee MH, Lee JW: Detection of hepatocellular carcinoma in gadoxetic acid-enhanced MRI and diffu sion-weighted MRI with respect to the severity of liver cirrhosis. Acta Radiol 2012;53:830-838.

57 Murakami T, Okada M, Hyodo T: CT versus MR imaging of hepatocellular carcinoma: toward improved treatment decisions. Magn Reson Med Sci 2012;11:75-81.

58 Kubota K, Tamura T, Aoyama N, Nogami M, Hamada N, Nishioka A, Ogawa Y: Correlation of liver parenchymal gadolinium-ethoxybenzyl diethylenetriaminepentaacetic acid enhancement and liver function in humans with hepatocellular carcinoma. Oncol Lett 2012;3:990-994.

59 Kobayashi S, Matsui O, Gabata T, Koda W, Minami T, Ryu Y, Kozaka K, Kitao A: Relationship between signal intensity on hepatobiliary phase of gadolinium ethoxybenzyl diethylenetriaminepentaacetic acid (GdEOB-DTPA)-enhanced MR imaging and prognosis of borderline lesions of hepatocellular carcinoma. Eur J Radiol 2012;81:3002-3009.

-60 Lee JM, Yoon JH, Joo I, Woo HS: Recent advances in CT and MR imaging for evaluation of hepatocellular carcinoma. Liver Cancer 2012;1:22-40.

61 Rhee H, Kim MJ, Park MS, Kim KA: Differentiation of early hepatocellular carcinoma from benign hepatocellular nodules on gadoxetic acid-enhanced MRI. Br J Radiol 2012;85:e837-e844.

62 Inoue T, Kudo M, Komuta M, Hayaishi S, Ueda T, Takita M, Kitai S, Hatanaka K, Yada N, Hagiwara S, Chung H, Sakurai T, Ueshima K, Sakamoto M, Maenishi O, Hyodo T, Okada M, Kumano S, Murakami T: Assessment of Gd-EOB-DTPA-enhanced MRI for HCC and dysplastic nodules and comparison of detection sensitivity versus MDCT. J Gastroenterol 2012;47:1036-1047.

-63 Sugimoto K, Moriyasu F, Saito K, Taira J, Saguchi T, Yoshimura N, Oshiro H, Imai Y, Shiraishi J: Comparison of Kupffer-phase Sonazoid-enhanced sonography and hepatobiliary-phase gadoxetic acid-enhanced magnetic resonance imaging of hepatocellular carcinoma and correlation with histologic grading. J Ultrasound Med 2012;31:529-538.

64 An C, Park MS, Jeon HM, Kim YE, Chung WS, Chung YE, Kim MJ, Kim KW: Prediction of the histopathological grade of hepatocellular carcinoma using qualitative diffusion-weighted, dynamic, and hepatobiliary phase MRI. Eur Radiol 2012;22:1701-1708.

65 Kim HY, Choi JY, Kim CW, Bae SH, Yoon SK, Lee YJ, Rha SE, You YK, Kim DG, Jung ES: Gadolinium ethoxybenzyl diethylenetriamine pentaacetic acid-enhanced magnetic resonance imaging predicts the histological grade of hepatocellular carcinoma only in patients with Child-Pugh class A cirrhosis. Liver Transpl 2012;18:850-857.

66 Watanabe H, Kanematsu M, Goshima S, Yoshida M, Kawada H, Kondo H, Moriyama N: Is gadoxetate disodium-enhanced MRI useful for detecting local recurrence of hepatocellular carcinoma after radiofrequency ablation therapy? AJR Am J Roentgenol 2012;198:589-595.

-67 Kinner S, Umutlu L, Blex S, Maderwald S, Antoch G, Ertle J, Gerken G, Lauenstein TC: Diffusion weighted MR imaging in patients with HCC and liver cirrhosis after administration of different gadolinium contrast agents: is it still reliable? Eur J Radiol 2012;81:e625-e628.

-68 Sugimoto K, Moriyasu F, Shiraishi J, Saito K, Taira J, Saguchi T, Imai Y: Assessment of arterial hypervascularity of hepatocellular carcinoma: comparison of contrast-enhanced US and gadoxetate disodium-enhanced MR imaging. Eur Radiol 2012;22:1205-1213.

-69 Korkusuz H, Knau LL, Kromen W, Bihrer V, Keese D, Piiper A, Vogl TJ: Different signal intensity at Gd-EOBDTPA compared with Gd-DTPA-enhanced MRI in hepatocellular carcinoma transgenic mouse model in delayed phase hepatobiliary imaging. J Magn Reson Imaging 2012;35:1397-1402.

-70 Eso Y, Marusawa H, Osaki Y: Education and imaging. Hepatobiliary and Pancreatic: Detection of early hepatocellular carcinoma by enhanced magnetic resonance imaging. J Gastroenterol Hepatol 2012;27:416.

-71 Alaboudy A, Inoue T, Hatanaka K, Chung H, Hyodo T, Kumano S, Murakami T, Moustafa EF, Kudo M: Usefulness of combination of imaging modalities in the diagnosis of hepatocellular carcinoma using Sonazoid $®$ enhanced ultrasound, gadolinium diethylene-triamine-pentaacetic acid-enhanced magnetic resonance imaging, and contrast-enhanced computed tomography. Oncology 2011;81(Suppl 1):66-72.

72 Hwang J, Kim SH, Lee MW, Lee JY: Small $(\leq 2 \mathrm{~cm})$ hepatocellular carcinoma in patients with chronic liver disease: comparison of gadoxetic acid-enhanced 3.0 T MRI and multiphasic 64-multirow detector CT. Br J Radiol 2012;85:e314-e322. 
73 Nakamura Y, Toyota N, Date S, Oda S, Namimoto T, Yamashita Y, Beppu T, Awai K: Clinical significance of the transitional phase at gadoxetate disodium-enhanced hepatic MRI for the diagnosis of hepatocellular carcinoma: preliminary results. J Comput Assist Tomogr 2011;35:723-727.

-74 Kim KA, Kim MJ, Jeon HM, Kim KS, Choi JS, Ahn SH, Cha SJ, Chung YE: Prediction of microvascular invasion of hepatocellular carcinoma: usefulness of peritumoral hy pointensity seen on gadoxetate disodiumenhanced hepatobiliary phase images. J Magn Reson Imaging 2012;35:629-634.

-75 Sano K, Ichikawa T, Motosugi U, Sou H, Muhi AM, Matsuda M, Nakano M, Sakamoto M, Nakazawa T, Asakawa M, Fujii H, Kitamura T, Enomoto N, Araki T: Imaging study of early hepatocellular carcinoma: usefulness of gadoxetic acid-enhanced MR imaging. Radiology 2011;261:834-844.

-76 Chanyaputhipong J, Low SC, Chow PK. Gadoxetate acid-enhanced MR imaging for HCC: A review for clinicians. Int J Hepatol 2011;2011:489342.

77 Rhee H, Kim MJ, Park YN, Choi JS, Kim KS: Gadoxetic acid-enhanced MRI findings of early hepatocellular carcinoma as defined by new histologic criteria. J Magn Reson Imaging 2012;35:393-398.

-78 Saito K, Moriyasu F, Sugimoto K, Nishio R, Saguchi T, Nagao T, Taira J, Akata S, Tokuuye K: Diagnostic efficacy of gadoxetic acid-enhanced MRI for hepatocellular carcinoma and dysplastic nodule. World J Gastroenterol 2011;17:3503-3509.

79 Baek CK, Choi JY, Kim KA, Park MS, Lim JS, Chung YE, Kim MJ, Kim KW: Hepatocellular carcinoma in patients with chronic liver disease: a comparison of gadoxetic acid-enhanced MRI and multiphasic MDCT. Clin Radiol 2012;67:148-156.

80 Chung J, Yu JS, Kim DJ, Chung JJ, Kim JH, Kim KW: Hypervascular hepatocellular carcinoma in the cirrhotic liver: diffusion-weighted imaging versus superparamagnetic iron oxide-enhanced MRI. Magn Reson Imaging 2011;29:1235-1243.

-81 Choi JY, Kim MJ, Park YN, Lee JM, Yoo SK, Rha SY, Seok JY: Gadoxetate disodium-enhanced hepatobiliary phase MRI of hepatocellular carcinoma: correlation with histological characteristics. AJR Am J Roentgenol 2011;197:399-405.

-82 Kim JE, Kim SH, Lee SJ, Rhim H: Hypervascular hepatocellular carcinoma $1 \mathrm{~cm}$ or smaller in patients with chronic liver disease: characterization with gadoxetic acid-enhanced MRI that includes diffusionweighted imaging. AJR Am J Roentgenol 2011;196:W758-65.

-83 Haradome H, Grazioli L, Tinti R, Morone M, Motosugi U, Sano K, Ichikawa T, Kwee TC, Colagrande S: Additional value of gadoxetic acid-DTPA-enhanced hepatobiliary phase MR imaging in the diagnosis of early-stage hepatocellular carcinoma: comparison with dynamic triple-phase multidetector CT imaging. J Magn Reson Imaging 2011;34:69-78.

84 Kim YK, Kim CS, Han YM, Yu HC, Choi D: Detection of small hepatocellular carcinoma: intraindividual comparison of gadoxetic acid-enhanced MRI at 3.0 and 1.5 T. Invest Radiol 2011;46:383-389.

85 Kagawa Y, Okada M, Kumano S, Katsube T, Imaoka I, Tanigawa N, Ishii K, Kudo M, Murakami T: Optimal scanning protocol of arterial dominant phase for hypervascular hepatocellular carcinoma with gadolinium-ethoxybenzyl-diethylenetriamine pentaacetic acid-enhanced MR. J Magn Reson Imaging 2011;33:864-872.

86 Kobayashi S, Matsui O, Gabata T, Koda W, Minami T, Ryu Y, Kawai K, Kozaka K: Gadolinium ethoxybenzyl diethylenetriamine pentaacetic acid-enhanced magnetic resonance imaging findings of borderline lesions at high risk for progression to hypervascular classic hepatocellular carcinoma. J Comput Assist Tomogr 2011;35:181-186.

87 Ariizumi S, Kitagawa K, Kotera Y, Takahashi Y, Katagiri S, Kuwatsuru R, Yamamoto M: A non-smooth tumor margin in the hepatobiliary phase of gadoxetic acid disodium (Gd-EOB-DTPA)-enhanced magnetic resonance imaging predicts microscopic portal vein invasion, intrahepatic metastasis, and early recurrence after hepatectomy in patients with hepatocellular carcinoma. J Hepatobiliary Pancreat Sci 2011;18:575-585.

88 Golfieri R, Renzulli M, Lucidi V, Corcioni B, Trevisani F, Bolondi L: Contribution of the hepatobiliary phase of Gd-EOB-DTPA-enhanced MRI to dynamic MRI in the detection of hypovascular small $(\leq 2 \mathrm{~cm}) \mathrm{HCC}$ in cirrhosis. Eur Radiol 2011;21:1233-1242.

89 Akai H, Kiryu S, Matsuda I, Satou J, Takao H, Tajima T, Watanabe Y, Imamura H, Kokudo N, Akahane M, Ohtomo K: Detection of hepatocellular carcinoma by Gd-EOB-DTPA-enhanced liver MRI: comparison with triple phase 64 detector row helical CT. Eur J Radiol 2011;80:310-315.

$\$ 90$ Bruix J, Sherman M American Association for the Study of Liver Diseases: Management of hepatocellular carcinoma: an update. Hepatology 2011;53:1020-1022.

$\$ 91$ European Association For The Study Of The Liver European Organisation For Research And Treatment Of Cancer: EASL-EORTC clinical practice guidelines: management of hepatocellular carcinoma. J Hepatol 2012;56:908-943.

$\$ 92$ Omata M, Lesmana LA, Tateishi R, Chen PJ, Lin SM, Yoshida H, Kudo M, Lee JM, Choi BI, Poon RT, Shiina S, Cheng AL, Jia JD, Obi S, Han KH, Jafri W, Chow P, Lim SG, Chawla YK, Budihusodo U, Gani RA, Lesmana CR, Putranto TA, Liaw YF, Sarin SK: Asian Pacific Association for the Study of the Liver consensus recommendations on hepatocellular carcinoma. Hepatol Int 2010;4:439-474.

$\checkmark 93$ Ricke J, Seidensticker M, Mohnike K: Noninvasive diagnosis of hepatocellular carcinoma in cirrhotic liver: current guidelines and future prospects for radiological imaging. Liver Cancer 2012;1:51-58.

$>94$ Bota S, Piscaglia F, Marinelli S, Pecorelli A, Terzi E, Bolondi L: Comparison of international guidelines for noninvasive diagnosis of hepatocellular carcinoma. Liver Cancer 2012;1:190-200.

-95 Kokudo N, Makuuchi M: Evidence-based clinical practice guidelines for hepatocellular carcinoma in Japan: the J-HCC guidelines. J Gastroenterol 2009;44(Suppl 19):119-121. 
96 Joishi D, Ueno A, Tanimoto A, Okuda S, Masugi Y, Emoto K, Okuma K, Sakamoto M, Imai Y, Kuribayashi S: Natural course of hypovascular nodules detected on gadoxetic acid-enhanced MR imaging: presence of fat is a risk factor for hypervascularization. Magn Reson Med Sci 2013;12:281-287.

97 Motosugi U: Hypovascular hypointense nodules on hepatocyte phase gadoxetic acid-enhanced MR images: too early or too progressed to determine hypervascularity. Radiology 2013;267:317-318.

$\$ 98$ Takechi M, Tsuda T, Yoshioka S, Murata S, Tanaka H, Hirooka M, Mochizuki T: Risk of hypervascularization in small hypovascular hepatic nodules showing hypointense in the hepatobiliary phase of gadoxetic acidenhanced MRI in patients with chronic liver disease. Jpn J Radiol 2012;30:743-751.

-99 Takayama Y, Nishie A, Nakayama T, Asayama Y, Ishigami K, Kakihara D, Ushijima Y, Fujita N, Hirakawa M, Honda H: Hypovascular hepatic nodule showing hypointensity in the hepatobiliary phase of gadoxetic acidenhanced MRI in patients with chronic liver disease: prediction of malignant transformation. Eur J Radiol 2012;81:3072-3078.

$\checkmark 100$ Akai H, Matsuda I, Kiryu S, Tajima T, Takao H, Watanabe Y, Imamura H, Kokudo N, Akahane M, Ohtomo $\mathrm{K}$ : Fate of hypointense lesions on Gd-EOB-DTPA-enhanced magnetic resonance imaging. Eur J Radiol 2012;81:2973-2977.

101 Motosugi U, Ichikawa T, Sano K, Sou H, Onohara K, Muhi A, Amemiya F, Enomoto N, Matsuda M, Fujii H, Araki T: Outcome of hypovascular hepatic nodules revealing no gadoxetic acid uptake in patients with chronic liver disease. J Magn Reson Imaging 2011;34:88-94.

102 Kumada T, Toyoda H, Tada T, Sone Y, Fujimori M, Ogawa S, Ishikawa T: Evolution of hypointense hepatocellular nodules observed only in the hepatobiliary phase of gadoxetate disodium-enhanced MRI. AJR Am J Roentgenol 2011;197:58-63.

103 Kudo M: Early hepatocellular carcinoma: definition and diagnosis. Liver Cancer 2013;2:69-72.

104 Arii S, Sata M, Sakamoto M, Shimada M, Kumada T, Shiina S, Yamashita T, Kokudo N, Tanaka M, Takayama T, Kudo M: Management of hepatocellular carcinoma: Report of Consensus Meeting in the 45th Annual Meeting of the Japan Society of Hepatology (2009). Hepatol Res 2010;40:667-685.

105 Kudo M: Treatment of advanced hepatocellular carcinoma with emphasis on hepatic arterial infusion chemotherapy and molecular targeted therapy. Liver Cancer 2012;1:62-70.

106 Kim YK, Kim CS, Chung GH, Han YM, Lee SY, Jin GY, Lee JM: Radiofrequency ablation of hepatocellular carcinoma in patients with decompensated cirrhosis: evaluation of therapeutic efficacy and safety. AJR Am J Roentgenol 2006;186(Suppl):S261-S268.

107 Kudo M, Osaki Y, Matsunaga T, Kasugai H, Oka H, Seki T: Hepatocellular carcinoma in Child-Pugh C cirrhosis: prognostic factors and survival benefit of nontransplant treatments. Dig Dis 2013;31:490-498.

108 Nishikawa H, Kita R, Kimura T, Ohara Y, Takeda H, Sakamoto A, Saito S, Nishijima N, Nasu A, Komekado H, Osaki Y: Clinical efficacy of non-transplant therapies in patients with hepatocellular carcinoma with ChildPugh C liver cirrhosis. Anticancer Res 2014;34:3039-3044.

109 Nouso K, Ito Y, Kuwaki K, Kobayashi Y, Nakamura S, Ohashi Y, Yamamoto K: Prognostic factors and treatment effects for hepatocellular carcinoma in Child C cirrhosis. Br J Cancer 2008;98:1161-1165.

110 Wakuta A, Nouso K, Kariyama K, Nishimura M, Kishida M, Wada N, Mizushima T, Higashi T, Tanimoto M: Radiofrequency ablation for the treatment of hepatocellular carcinoma with decompensated cirrhosis. Oncology 2011;81:39-44.

111 Raoul JL, Gilabert M, Piana G: How to define transarterial chemoembolization failure or refractoriness: a European perspective. Liver Cancer 2014;3:119-124. 